\title{
Studying the Reinforcement Effect of a Seminar on Ethical Practices among Pediatric Nurses
}

\author{
Naomi Matsumori $\mathbb{B}$ \\ Department of Nursing, Faculty of Health and Welfare, Prefectural University of Hiroshima, Hiroshima, Japan \\ Email: matumori@pu-hiroshima.ac.jp
}

How to cite this paper: Matsumori, N. (2021) Studying the Reinforcement Effect of a Seminar on Ethical Practices among Pediatric Nurses. Open Journal of Nursing, 11, 152-163.

https://doi.org/10.4236/ojn.2021.113014

Received: February 22, 2021

Accepted: March 20, 2021

Published: March 23, 2021

Copyright $\odot 2021$ by author(s) and Scientific Research Publishing Inc. This work is licensed under the Creative Commons Attribution International License (CC BY 4.0).

http://creativecommons.org/licenses/by/4.0/

\section{(c) (i) Open Access}

\begin{abstract}
Aim: This study aimed to examine the effect of a seminar to continuously reinforce ethical nursing practices among pediatric nurses. Methods: This seminar was based on a 24-point pediatric nursing care model (PNCM) that provided specific examples of basic ethical nursing practices for children undergoing medical procedures and their families. Participants' knowledge level and application frequencies, regarding these practices, were assessed face-to-face in the first session and via email 2 and 5 months later, using the PNCM checklist and qualitative data about ethical practices. Results: Results revealed that 8 PNCM items about frequency remained the same as the first session after 5 months; however, 16 items reported increased application. The qualitative data collected 2 months later suggested that the nurses could have adapted better to implement ethical pediatric nursing; however, the one collected 5 months later confirmed the effect of the seminar on ethical nursing practices with children and their families. The continuous effect of the seminar became more evident from the responses received 5 months later than those received 2 months later. Conclusions: The findings confirmed a reinforced effect on ethical pediatric nursing practice with child patients and their parents after 5 months.
\end{abstract}

\section{Keywords}

Ethical Nursing Practice, Pediatric Nursing Care Model, Seminar, Checklist, Reflection

\section{Background}

According to a survey conducted by Japan's Ministry of Health, Labour and Welfare, the total number of all Japanese hospitals with pediatric departments, has decreased from $45.7 \%$ (4119 facilities) in 1990 to $35 \%$ (2539 facilities) in 
2019 [1]. Additionally, the average term of hospitalization has also shortened from 14.7 days (1990) to 7.5 days (2017) [1]. A possible reason, for this decrease in the number of pediatric departments and the hospitalization term, could be the reduction in child birthrate and the improvement in medical skills. Moreover, the Japanese government needs to control the allocation of medical budget and hospital beds for inpatients. According to Kobayashi et al. [2], about 70\% of hospitals that provide pediatric care have mixed wards that include child and adult patients; furthermore, the number of mixed wards in pediatric departments has rapidly increased since 1994. Thus, with the increase in trends of short-term hospitalization and the number of mixed wards, it is essential to maintain the expert quality of nursing in various pediatric care services. However, there is a discrepancy in the expertise of pediatric nurses in medical facilities, such as the differences in ethical nursing practice, by those who are unaware of the procedures to engage with the children and families in mixed wards, and quality issues in childcare and education. In 2010, clinical training for new nursing staff became mandatory in Japan, and the "Guidelines for Training New Nursing Staff” were formulated [3]. However, there are no systematic training programs for beginners in pediatric nursing practice, such as nursing training specific to mixed wards pediatric departments. In addition, several reports have highlighted the need for practical education on ethical nursing practices for children and families in mixed wards, to be implemented among nurses after their graduation; no systematized reports have been conducted for the same [4] [5].

After Japan's ratification of the Convention on the Rights of the Child in 1994, the Japanese nursing field was introduced to psychological preparation, with the aim of promoting ethical nursing practices for children [6]. Takahashi, a scale developer, provided three factors to facilitate the promotion of child advisory guidelines among pediatric nurses in "The ability of recovering child advisory for pediatric nurses" as follows: 1) activities to understand and support children and their families, 2) ability to change the mindset of medical staff who did not advocate for children's rights, and 3) activities to explain to the child and confirming his or her own view [7]. Similarly, Omori conducted a survey among Japanese nursing colleges and reported that all 56 pediatric nursing teachers (participants) taught about preparing children in their lectures and practical training [8]. However, previous Japanese research revealed that the implementation rate was only $10 \%$ to $50 \%$; this low rate was due to the economic and time constraints on implementing the preparation guidelines, on account of the lack of tools for evaluating children's explanations and psychological preparation because of time and budget constraints among nurses and in hospitals, respectively [9].

Additionally, it has been pointed out that in Ireland, nurses are expected to show sensitivity toward children's rights and their emotional and informational needs; furthermore, a child-centered environment, with good communication 
between children and nurses, needs to be created, as it aids in reducing the pain caused from treatments [10]. In order to facilitate children's voluntary participation in healthcare, their involvement in the decision-making process and the perception of "choices" are fundamental; these include others wanting to share the process with parents and medical professionals making more serious decisions. Several reports support children's right to participate; however, improving the quality of medical care through children's participation remains an operational challenge. Furthermore, previous research has suggested that nursing education should nurture and develop nurses' abilities to manage the interactions between children, parents, and healthcare personnel [10]. This study also revealed that pediatric nurses in hospitals have limited time to provide care and communicate the environmental challenges to the children, who are away from their families. In addition, he reports these particularly important issues for hospitalized children: 1) nursing for infants, 2) isolation from the family, 3) strained family relationships, 4) difficulties due to environmental and ward design, and 5) lack of play experiences. Moreover, sometimes, pediatric nursing training does not cater to children's specific needs while caring for them; it has also been suggested that the medical care provided by post-graduate nurses may affect the hospital experience of children and their families [11].

Bets et al. [12] reported that the Child, Adolescent and Family Expert Panel of the American Academy of Nursing (AAN) has been developing and revising nursing guidelines for children, adolescents, and their families for the last 15 years. These guidelines are frameworks for performing nursing services and interventions, which include: 1) a curriculum development model for undergraduate and postgraduate children and child health nursing programs and 2) a theoretical model for nursing surveys regarding the care of children, adolescents, and families. The most recent revisions accommodated family centered, people-first, and cultural sensitivity and language diversity changes. Through these revisions, the privacy and rights of children, youth, and their families are protected, and healthcare providers are viewed as partners in decision-making, planning, and providing care, including appropriate community services.

\section{Introduction}

In Japan, Taguchi says that nurses can be aware of the ethical issues of children and families and have a perspective to search for solutions through experiences that cannot be solved. In addition, nurses need to have ethical judgment skills and voluntarily cooperate with others to tackle ethical dilemmas in their daily nursing practice [13]. The Japanese Society of Child Health Nursing (2010) released the "Guidelines on Ethical Issues in The Everyday Clinical Setting of Pediatric Nursing" for advocating the importance of communication, trust, and decision-making support between children and their families. It recommends that ethical issues should be discussed amongst team members and improved practical solutions should be found for children [14]. Therefore, with the de- 
crease in pediatrics and introduction of mixed wards, there is an urgent need to strengthen the ethical nursing practices for children and their families, and to provide learning opportunities for nurses with limited experience in pediatric nursing. For this purpose, we have evaluated the effectiveness of a seminar, conducted since 2012, based on a 24-point pediatric nursing care model (PNCM). This model provides specific examples of basic ethical nursing practices for children, undergoing medical procedures, and their families [15] [16]. In this study, we re-conducted a similar seminar, and examined its effects at three separate intervals up to 5 months. I would like to present the results for the continuous education of pediatric nursing for nurses working in both the pediatric and mix wards departments.

\section{Objective}

The aim of this study was to examine the effect of the seminar on reinforcing ethical nursing practices among nurses working in pediatric departments.

\section{Method}

\subsection{Participants}

Invitations were sent to 11 general hospitals and 1 clinic, in the rural areas of the west of Japan, for participating in this study. A total of 21 nurses, working in the pediatric department, were recruited before the first session.

\subsection{Procedure and Data Collection}

Participants were asked to complete the PNCM checklist, before the first seminar session, by indicating their frequency of PNCM usage. They responded to the checklist using a 4-point Likert-type scale (1: never; 2: rarely; 3: almost always; 4: always). Participants, then, attended a 30-minute mini-lecture; the lecture highlighted the theoretical understanding and the necessity of PNCM. Participants were requested to complete a form with reference to examples from their current practice. After an interval of 2 months, another PNCM checklist and practice form were mailed to the participants; they were asked to complete and return them to the researcher.

The results of the first and the second forms were mailed to the participants, along with positive feedback they were also asked to complete a third PNCM checklist.

The seminar was held in 2018 and 2019, and data was collected until March 2020. The first session data was collected at the seminar, while the other data was collected via mail. Data from each PNCM checklist and practice example form were used to analyze the effect of the 30-minute mini-lecture intervention. Each data and description was part of the intervention program.

\subsection{Analysis}

Quantitative data on the frequency of PNCM items were aggregated using $\mathrm{Mi}$ - 
crosoft Excel (2013). The median values were compared. A qualitative inductive analysis was performed using the data obtained from respondents' practice examples, and their responses regarding ethical nursing practices for children and their family, from the first session to 5 months later. The inductive analysis categories were validated through repeated reading and analysis until theoretical saturation was achieved.

\subsection{Ethical Considerations}

Participation in the study was voluntary. At the beginning of the session, the study purpose was explained and participants provided informed consent. Participants were assured of anonymity. This study was approved by the research ethics review committee of the institute the researcher belonged to (No. 18MH002).

\section{Result}

\subsection{Participant Characteristics (See Figure 1, Table 1)}

A total of 21 nurses agreed to participate in this study. Of these, 6 nurses (28.6\%) participated only in the first session, 3 nurses (14.3\%) participated up to 2 months later, and 12 nurses (57.1\%) participated up to the end of the study, 5 months later. Moreover, of these, 1 had work experience only in pediatric nursing, and 20 in other nursing areas, such as adult patient departments. The average pediatric nursing experience (years) of the 6 nurses, who participated only in the first session, was 1.3 years. Similarly, those who participated up to 2 months $(\mathrm{n}=3)$ and 5 months later $(\mathrm{n}=12)$, had a nursing experience of 6.8 and 5.9 years, respectively. Most of the participants had learnt nursing ethics; however, only $50 \%$ and $33.3 \%$ of the participants from the first session and 5 months later, respectively were aware of the Code of nursing ethics. $50 \%$ of the first session only participants had learnt about psychological preparation; this proportion was $58.3 \%$ among those who participated 5 months later.

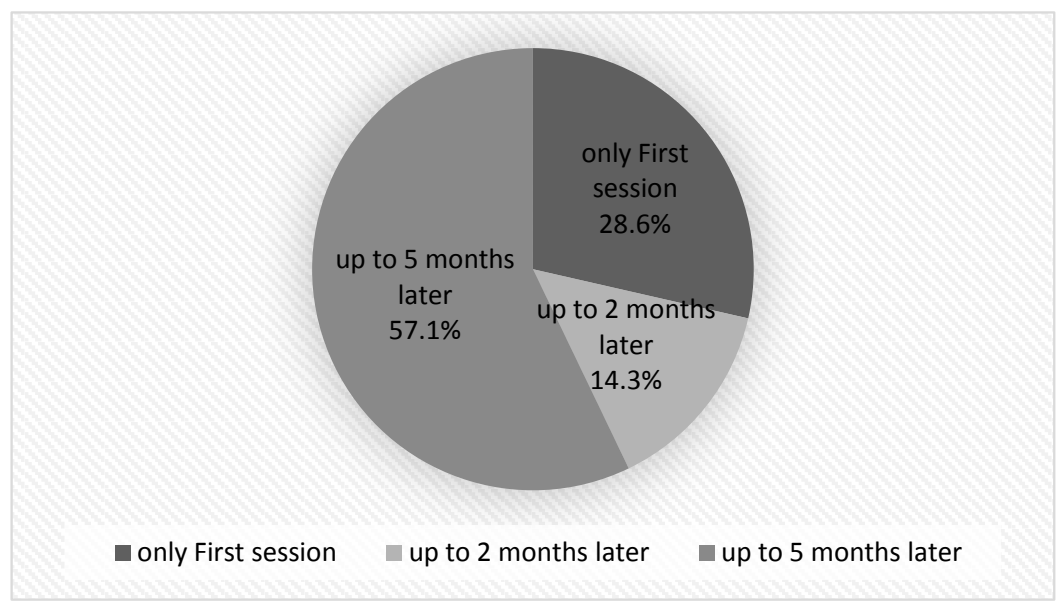

Figure 1. Participant characteristics. 
Table 1. Participant characteristics of each participation duration group.

\begin{tabular}{|c|c|c|c|}
\hline & Up to five months later $(n=12)$ & Up to two months later $(n=3)$ & Only first session $(n=6)$ \\
\hline Average nursing experience (years) & $15.2(\mathrm{SD}=9.0)$ & $11.8(\mathrm{SD}=5.2)$ & $12.5(\mathrm{SD}=7.6)$ \\
\hline Average pediatric nursing experience (years) & $5.9(\mathrm{SD}=5.4)$ & $6.8(\mathrm{SD}=3.7)$ & $1.3(\mathrm{SD}=0.9)$ \\
\hline Experience of various nursing areas & $11(91.7 \%)$ & $3(100 \%)$ & $6(100 \%)$ \\
\hline Learning experience about nursing ethics & $10(83.3 \%)$ & $3(100 \%)$ & $6(100 \%)$ \\
\hline Knowledge about the Code of nursing ethics & $4(33.3 \%)$ & $2(66.7 \%)$ & $3(50.0 \%)$ \\
\hline Learning experiences of psychological prepara & $77(58.3 \%)$ & $3(100 \%)$ & $3(50.0 \%)$ \\
\hline Reason for participation & $\begin{array}{l}\text { - I want to learn good involvement } \\
\text { with child patient and their family. } \\
\text { - I try to reflect of my own nursing. } \\
\text { - I want to learn more deeply. } \\
\text { - Nurse director recommended to } \\
\text { participate the session. } \\
\text { - I want to learn about pediatric } \\
\text { nursing. } \\
\text { - I want to apply to clinical } \\
\text { instruction for students and juniors. } \\
\text { - I want to implement better } \\
\text { preparation for children. } \\
\text { - I want to apply to regular nursing } \\
\text { duty work. } \\
\text { - We have no seminar of pediatric } \\
\text { nursing in our hospital. }\end{array}$ & $\begin{array}{l}\text { - I want to apply to my nursing } \\
\text { about involvement with child } \\
\text { patient. } \\
\text { - I try to reflect of my own } \\
\text { nursing. } \\
\text { - I want to find my shortage of } \\
\text { nursing practice }\end{array}$ & $\begin{array}{l}\text { - I want to learn about } \\
\text { involvement with child } \\
\text { patient, because of } \\
\text { shortage of pediatric } \\
\text { nursing experience. } \\
\text { - I want to learn about } \\
\text { pediatric nursing more } \\
\text { deeply. }\end{array}$ \\
\hline
\end{tabular}

Those who participated only in the first session, stated their reason for participation as: "I want to learn about involvement with child patients, because of a shortage of pediatric nursing experience." Similarly, those who participated up to 2 and 5 months later stated their reason for participation as: "I want to learn about engaging with child patients and their families," "I try to reflect on my own nursing practice," and "We have no seminar on pediatric nursing in our hospital."

\subsection{Reflection Categories on Practice Example Forms in the First Session and 2 Months Later (See Table 2)}

Descriptive statistics were used to divide the practice example form responses, from the first session and 2 months later, into six categories. Common categories for both conditions were "Regret and reflection of involvements with children," "Regret and reflection of involvements with parents," "Necessity of restraining the child for safety," and "Effective cooperation with parents." Furthermore, the categories for first session included: "Implementing consultation with children," and "Relief from the words of children," while those for 2 months later included: "Effective implementation for children" and "Motivation for effective implementation," which indicated nurses' active thoughts about duty work as well as effective ethical practice. 
Table 2. Reflection categories on practice example forms in the first session and 2 months later.

\begin{tabular}{ccc}
\hline First session & $\mathrm{n}$ & Two months later \\
\hline $\begin{array}{c}\text { Regret and reflection of involvements with children } \\
\text { Regret and reflection of involvements with parents }\end{array}$ & 16 & Regret and reflection of involvements with children \\
Necessity of restraining the child for safety & 4 & Effective implementation for children \\
Effective cooperation with parents & 3 & Regret and reflection of involvements with parents \\
Implementing consultation with children & 2 & Effective cooperation with parents \\
Relief from the words of children & 2 & Necessity of restraining the child for safety \\
\end{tabular}

\subsection{Categories for Ethical Nursing Practices with Children and Their Family from the First Session to 5 Months Later (See Table 3)}

The categories for responses about the ethical nursing practices implemented by participants are presented in Table 3.

The common categories, from the first session and 5 months later, included: "Explain the procedure to children," "Don't lie to children," "Listen to children's opinions and feelings," "Listen to their family's thoughts," "Explain the procedure to their family," and "Do not force the child."

Moreover, responses from the first session were categorized into: "Confirm and implement the consent of the medical procedure" and "apologize to parents for failure to draw blood," while those for responses from 5 months later included: "Confirm the understanding of children and parents and set goals together," "See the child's usual situation and reaction," and "Check the implementation status of PNCM."

\subsection{The Frequency Change in PNCM Items (See Figure 2)}

The median frequency of PNCM responses of 12 participants, who participated up to five months later were computed; these values were compared for the responses from the first session, 2 months later, and 5 months later. Results revealed that the median frequency of 8 items were the same as in the first session, 5 months later, but those of 16 items increased, compared to the first session.

The item 16 "When the examinations/procedures take longer than expected, you give parents an update on their progress" reported increases 2 months later, but decreased 5 months after the first session.

\section{Discussion}

\subsection{Necessity of Specialized Training in Pediatric Care}

Nurses who participated only in the first session had lesser experience in pediatric nursing than those who continued their participation and were motivated by their want to learn about building relationships with child patients, due to the lack of pediatric nursing experience. However, those who continued up to 2 or 5 months later had more experience in pediatric nursing and psychological preparation and had a higher motivation to continue their participation. They re- 
sponded with: "We have no seminar of pediatric nursing in our hospital." Japanese nursing education only includes a general nursing program. Post their graduation, many Japanese nurses work in pediatric departments, where they receive specialized training in pediatric care [15]. However, the participant responses reveal that some hospitals have no training systems in pediatric care. On the other hand, in Western countries, nursing education systems provide pediatric nursing specializations. Thus, nurses for children and young people remain committed to preserving the integrity of their profession through the direct entry mode of education in the UK [17]. On the other hand, nursing education and continuing education are practiced using decision-making models in the United States, and practices compatible with the hospital guidelines have been reported [18]. Therefore, it is necessary to conduct specialized and systematic pediatric nursing training for all nurses working in pediatric departments.

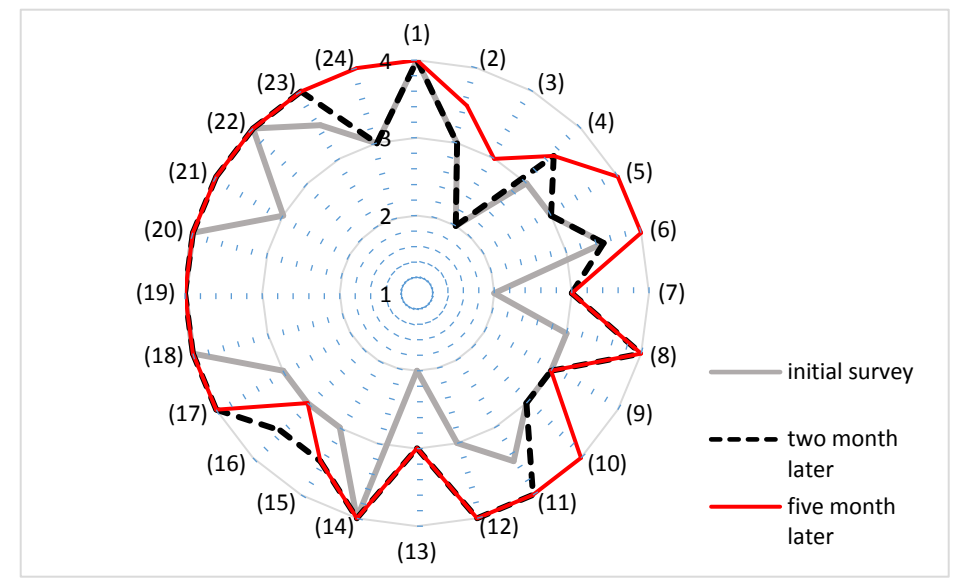

Figure 2. Changes in the frequency of PNCM items between the initial survey, 2 months, and 5 months later.

Table 3. Categories of ethical nursing practices for children and their family from the first session to 5 months later.

\begin{tabular}{|c|c|c|}
\hline First session & Two months later & Five months later \\
\hline Explain the procedure to children & & Explain the procedure to children \\
\hline Explain the procedure to their family & & Explain the procedure to their family \\
\hline Do not lie to children & Communicate children's efforts to themselves & Do not lie to children \\
\hline Do not force the child & and their families Acknowledge children's & Do no force the child \\
\hline Listen to children's opinions and feelings & efforts & Listen to children's opinions and feelings \\
\hline Listen to their family's thoughts & Distract and reduce anxiety & Listen to their family's thoughts \\
\hline Communicate children's efforts to themselves & & Acknowledge children's efforts \\
\hline and their families & & Distract and reduce anxiety \\
\hline Introduce yourself to children and their family & & See the child's usual situation and reaction \\
\hline $\begin{array}{l}\text { Confirm and implement the consent of the } \\
\text { medical procedure }\end{array}$ & & $\begin{array}{c}\text { Confirm the understanding of children and parents } \\
\text { and set goals together }\end{array}$ \\
\hline $\begin{array}{l}\text { Tailored to the life and hopes of children and } \\
\text { families }\end{array}$ & & Over voice to consider the children \\
\hline Apologies to parents for failure to draw blood & & Check the implementation status of PNCM \\
\hline Check if the doctor explained & & \\
\hline
\end{tabular}




\subsection{Continuous Effect of the Seminar}

Participants provided qualitative data to reflect their current practice examples. "Effective implementation for children" and "motivation for effective implementation" on the practice example forms. The results suggested that the nurses could have adapted more active pediatric nursing practices, due to higher subjective attitudes in response categories 2 months later than those from the first session. The median frequency of responses increased on 16 items of the PNCM checklist, 5 months later, compared with the first session responses. These items included subjective nursing attitudes on the categories of ethical practices such as: "Confirm the understanding of children and parents and set goals together," "See the child's usual situation and reaction," and "Check the implementation status of PNCM." Pediatric nursing education should include fundamentals of children's nursing such as the subtleties of communication with the child, who is unique and dynamic in their development, and the recognition of every nursing encounter as an opportunity to improve the health knowledge and skills of the child and their family [17]. These fundamentals of children's nursing were reported in the responses 5 months later. Previous studies have already confirmed the effect of the seminar 3 months later, but this study proved that the effect lasted longer after participating in the seminar on children's nursing education [16]. Additionally, the PNCM checklist and the practice example forms were effective in reinforcing ethical nursing practices. Organizations around the world are developing codes of ethics to serve as behavioral guidelines for nurses. Each country revises its own code of ethics based on the local and national healthcare and social changes. Currently, it is said that ethical competence education does not comprehensively cover the Code of Ethics, and the level of competence cannot be gauged during basic nursing education [19]. In this study, most participants had the learnt about nursing ethics; however, only $33.3 \%$ of the participants up to 5 months were aware of the Code of nursing ethics. Therefore, it is deemed necessary to put forth a progressive educational program to develop ethics seminar and training that provides basic nursing education through continuing nursing education. Future research needs to develop the ethical nursing practice further and confirm the continuous effects for longer than 5 months.

\subsection{Study Limitations}

The current study results are based on the subjective perception of the participants, as data was self-reported by nurses. Therefore, it is necessary for future research to observe medical procedures or interview the children, who have undergone these procedures, and their parents. Additionally, good mentoring is important for child nurses, as it is a determinant factor in building a positive clinical environment [17]. However, in this study, we could not provide mentorship face to face. The results of the first session and 2 months later were mailed to the participants, 5 months after the intervention, along with positive comments. The Internet provides accessibility to higher education; it is based on 
a complex pedagogy that enables student engagement, choice and expression of diverse views, emergent learning, and personal discovery [20]. Therefore, future studies should design and examine the effects of seminars with good mentorship face to face or through an electronical or an internet tool. Additionally, the contents of the seminar should be tailored to the needs of participants, such as nursing skills training or nursing knowledge about pediatric disease, and so on. Furthermore, the sample size in this study was small. Future research should collect data from a larger sample of participants by accommodating the nursing shifts of each hospital, while determining the seminar timings.

\section{Conclusion}

The seminar implemented in this study, uses a 24-point PNCM that provides specific examples of basic ethical nursing practices for children, receiving medical procedures, and their families. A total of 21 nurses participated in the first session, of whom 12 nurses participated up to 5 months later (57.1\%). This study verified the effect of the seminar to continuously reinforce ethical nursing practices among nurses working at pediatric department. Eight PNCM items reported the same frequency 5 months later as the first session, but 16 items reported increased frequency, compared with the first session. Two months later, the nurses felt better equipped to implement more active pediatric nursing. Furthermore, the effect of the seminar was confirmed 5 months later through statements, such as "Confirm the understanding of children and parents and set goals together", "See the child's usual situation and reaction", and "Check the implementation status of PNCM". The continuous effect of the seminar was more apparent in the responses from 5 months later than those from 2 months later. I would like to present the results of the current study, as a method of continuous education for nurses working in both the pediatric and mix wards departments.

\section{Acknowledgements}

I would like to express my sincere gratitude toward the nurses working in pediatric departments, who participated in this study. This study was funded by a research grant from the Japan Society for the Promotion of Science (2017-22).

\section{Conflicts of Interest}

The author declares no conflicts of interest regarding the publication of this paper.

\section{References}

[1] Ministry of Health, Labour and Welfare (2019) Survey of Health Institutions in Japan. https://www.mhlw.go.jp/toukei/saikin/hw/iryosd/19/dl/02sisetu01.pdf

[2] Kobayashi, K. and Hohashi, N. (2013) A Nationwide Survey on the Current Status of Family Accompaniment/Visits to Hospitalized Children, and Difficulties and 
Challenges Encountered by Nurses in Family Care. Journal of Japanese Society of Child Health Nursing, 22, 129-134. (In Japanese)

[3] Ministry of Health, Labour and Welfare (2014) The Guidelines Given by the Government of the Program of Newcomers of Nursing Staff. (In Japanese) https://www.mhlw.go.jp/file/06-Seisakujouhou-10800000-Iseikyoku/0000049466_1. pdf

[4] Kobayashi, Y., Hoshi, N., Shimoda, T. and Sugiyama, T. (2008) Awareness and Actions of Nurses Who Come into Contact with Hospitalized Children: Focusing on What Is in the Children's Best Interest. Journal of Health Care and Nursing, 4, 10-19. (In Japanese)

[5] Ishiura, M., Machida, W. and Sakamoto, M. (2012) Nursing Ethics in Mixed Wards. Pediatric Nursing, 35, 986-993. (In Japanese)

[6] Mastumori, N., Ebina, M., Konno, M., Sugimoto, Y., Naragino, H., Sato, Y., Okada, Y., Takahashi, S. and Hashimoto, Y. (2011) Parents' Thoughts about Psychological Preparation for Children Who Have Undergone Surgery. Journal of Japanese Society of Child Health Nursing, 20, 1-9. (In Japanese)

[7] Takahashi, K. and Takita, K. (2019) Development of the Ability Scales of Regarding Child Advocacy for Pediatric Nurses: Analysis of Reliability and Validity. Journal of Japanese Nursing Ethics, 11, 30-39. (In Japanese)

[8] Omori, H., Iwase, K. and Tomoda, H. (2017) The State on Preparation in Baccalaureate Nursing Programs. Journal of Japanese Society of Child Health Nursing, 26, 132-137. (In Japanese)

[9] Matsumori, N. (2016) Nurse's Impressions and Changes after the Workshops Using the Pediatric Nursing Care Model. Journal of Nursing Education and Practice, 6, 82-89. https://doi.org/10.5430/jnep.v6n9p82

[10] Clarke, S. (2015) A "Child's Rights Perspective": The "Right" of Children and Young People to Participate in Health Care Research. Issues in Comprehensive Pediatric Nursing, 38, 161-180. https://doi.org/10.3109/01460862.2015.1042171

[11] Clarke, S. (2019) Children's Experiences of Staying in Hospital from the Perspectives of Children and Children's Nurses: A Narrative Review. Nursing and Health Care, 4, 62-70. https://doi.org/10.33805/2573.3877.141

[12] Betz, C.L., Cowell, J.M., Faulkner, M.S., Feeg, V.D., Greenberg, C.S., Krajicek, M.J., Lipman, T.H., Lobo, M.L., Nehring, W.M., Craft-Rosenberg, M. and Vessey, J.A. (2016) Advancing the Development of the Guidelines for the Nursing of Children, Adolescents, and Families: 2014 Revision: Process, Development, and Dissemination. Journal of Pediatric Health Care, 30, 284-288.

https://doi.org/10.1016/j.pedhc.2015.11.003

[13] Taguchi, S., Nagashima, S., Uehara, K., Yamoto, M. and Touma, N. (2020) The Process of Pediatric Nurses' Ethical Problem Solves. The Okinawa Journal of Child Health, 47, 25-32. (In Japanese) http://www.osh.or.jp/in_oki/pdf/47gou/houkoku.pdf

[14] Japanese Society of Child Health Nursing (2010) Guidelines on Ethical Issues in the Daily Clinical Scene of Pediatric Nursing. Japanese Society of Child Health Nursing. (In Japanese) https://jschn.or.jp/files/100610syouni_shishin.pdf

[15] Matsumori, N. (2019) Effects of an Intervention Program for Promoting Ethical Practices among Pediatric Nurses. Comprehensive Child and Adolescent Nursing, 42, 203-221. https://doi.org/10.1080/24694193.2018.1470704

[16] Matsumori, N. (2020) An Ethical Practice Intervention Program for Pediatric Nurses with Varied Nursing Experience. Open Journal of Nursing, 10, 411-428. 
https://doi.org/10.4236/ojn.2020.104028

[17] Clark, S., Glasper, A. and Richardson, J. (2017) Considering the Future Direction of Children's and Young People's Nursing. British Journal of Nursing, 26, 1042-1043. https://doi.org/10.12968/bjon.2017.26.18.1042

[18] Murray, K., Yasso, S., Schomburg, R., Terhune, M., Beidelschies, M., Bowers, D. and Goodyear-Bruch, C. (2016) Journey of Excellence: Implementing a Shared Decision-Making Model. AJN The American Journal of Nursing, 116, 50-56. https://doi.org/10.1097/01.NAJ.0000482137.12424.51

[19] Yoshioka, E. and Kaneko, S. (2019) The Acquisition of Ethical Competence in Basic Education and the Present State of Ethics Education. Open Journal of Nursing, 9, 676-686. https://doi.org/10.4236/ojn.2019.97052

[20] Mitchell, G.J., Pilkington, F.B., Daiski, I. and Cross, N. (2017) Complexity-Based Pedagogy for E-Learning: Description of Emergence in a Graduate Nursing Program. Open Journal of Nursing, 7, 222-241. https://doi.org/10.4236/ojn.2017.72019 